\title{
The Design of the Benchmark Land Price Release and Management Information System Based on Webgis
}

\author{
Kong Hui ${ }^{1,2,3,4}$, Shi Lei ${ }^{1,2,3,4}$ \\ ${ }^{1}$ Shaanxi Provincial Land Engineering Construction Group Co., Ltd., Xi'an, 710075, China \\ ${ }^{2}$ Institute of Land Engineering and Technology, Shaanxi Provincial Land Engineering Construction Group Co., Ltd., Xi'an, 710021, China \\ ${ }^{3}$ Key Laboratory of Degraded and Unused Land Consolidation Engineering, the Ministry of Land and Resources, Xi'an, 710021, China \\ ${ }^{4}$ Shaanxi Provincial Land Consolidation Engineering Technology Research Center, Xi'an, 710021, China
}

\begin{abstract}
The In this paper, on the premise of benchmark land price production data and, starting from the management and application direction of technology based on JavaScript, Java Web technology and ArcGIS for Server technology, the WebGIS system design, the MVC development mode, B/S (browser/Server) multi-tier architecture model design to achieve the collection of maps, land management, land price data query, data statistical analysis, and system integrated management and so on five big modules as one of the benchmark land price distribution and management information system.
\end{abstract}

Keywords: WebGIS, land price information, JavaScript, ArcGIS for Server.

\section{Introduction}

Land Information System (LIS) based on WebGIS technology is an inevitable product of the reform and development of the land industry bred by the combination of land resources, computer science and geographic information science, in which the emergence of regional professional systems such as urban land grading and valuation system, urban land price publication and management information system and urban land price dynamic monitoring system also greatly illustrates the great achievements of science and technology and The emergence of these regional professional systems, such as the urban land valuation system, the urban land valuation publication and management information system, and the urban land valuation dynamic monitoring system, has also greatly demonstrated the great achievements of science and technology in the utilization and management of land resources, and has brought convenience to the government, professional practitioners, and even the general public, improving the management and decision-making efficiency of government departments, the professionalism of practitioners, and two-way communication and information sharing with the general public.

\section{Overall System Design}

Based on the design concept of Open Service Oriented Architecture (SOA), the Benchmark Land Value Information Release and Management Information System is a multifunctional application system based on WebGIS technology and $\mathrm{B} / \mathrm{S}$ architecture, consisting of a three-layer architecture of data layer, logic layer (business layer) and application layer

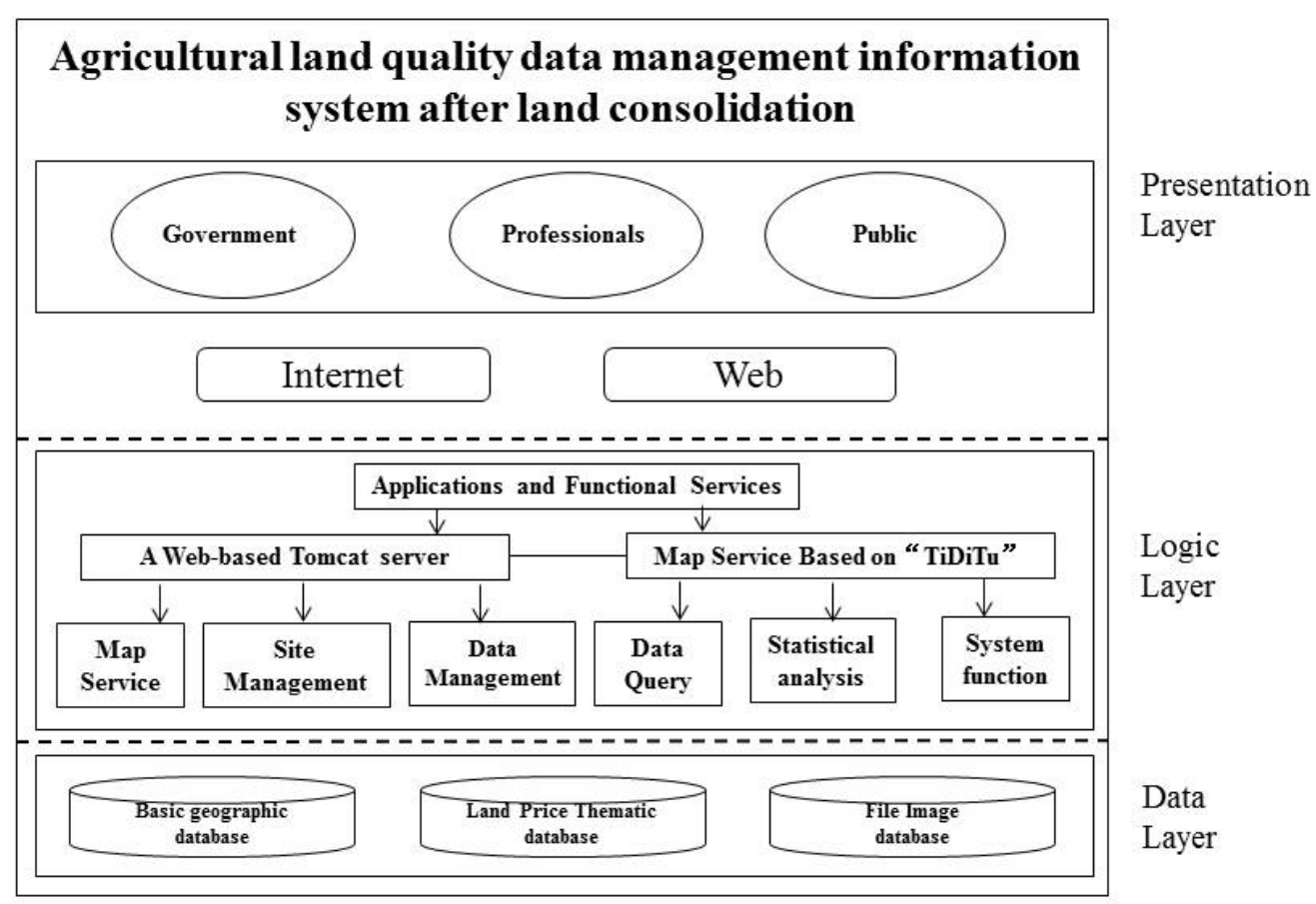

Figure 1. System architecture diagram 


\subsection{Data Layer}

The data layer of this system adopts PostgreSQL as the database management system and connects the spatial database of GIS and PostgreSQL database through ArcSDE (spatial database engine) to store the spatial data and attribute data related to land value data, basic geographic data, monitoring point data, sample point data and other data forms such as graphics, tables and multimedia data in the database server for unified management.

\subsection{Logic Layer}

On the basis of database creation, the relevant land value information data, monitoring point data and land value sample point data are published as map data services by standard services such as WMS, WCS and WFS through ArcGIS for Server technology, and Tomcat technology is used as a web service container to provide data from the data layer to the application layer according to business requirements to realize the operation of the data, thus realizing the three main functional modules of map basic operation, query analysis and data management, and playing an interactive role with users.

\subsection{Application Layer}

The application layer is the front-end interface of the system and the visual representation of the browser, including PC computers, mobile tablets, cell phones, etc., can interact with the system through the browser. This layer requires the logical layer to transfer the relevant data provided by the data layer to the application layer in the foreground through logical business processing, and the application layer expresses the processed data in an appropriate form. This system uses ArcGIS API for JavaScript, a set of front-end API presentation modes, to achieve better user interaction and the best visual representation of the basic data, in addition to For database updates, the new data is also returned to the database from the application layer as the entry point.

Table 1. The system software and hardware configuration

\begin{tabular}{|c|c|}
\hline Type & Specify \\
\hline $\begin{array}{l}\text { The hardware } \\
\text { system }\end{array}$ & $\begin{array}{l}\text { Intel Core } \mathrm{I} 3 \text { processor (dual } \\
\text { core } 3.70 \mathrm{GHz} \text {, } 8 \mathrm{gb} \text { of ram }\end{array}$ \\
\hline $\begin{array}{l}\text { The operating } \\
\text { system }\end{array}$ & $\begin{array}{l}\text { Windows7 flagship version } \\
\text { 64bit }\end{array}$ \\
\hline $\begin{array}{l}\text { Development } \\
\text { platform }\end{array}$ & $\begin{array}{l}\text { Myeclipse, Webstorm, } \\
\text { Dreamweaver }\end{array}$ \\
\hline The database & MySQL5.5 \\
\hline The Web server & $\begin{array}{c}\text { Struts2, Hibernate } 3.5 \\
\text { Spring4.0, Tomcat8 }\end{array}$ \\
\hline The GIS server & Map world online API service \\
\hline The client & $\begin{array}{c}\text { EChart, Jquery, AJAX, Know } \\
\text { the weather API }\end{array}$ \\
\hline The UI & $\begin{array}{l}\text { Photoshop and query easyui } \\
\text { plug-ins }\end{array}$ \\
\hline
\end{tabular}

\section{System Function Design}

The system function modules are an important part of the operation of the whole benchmark land value inquiry and management information system. Based on the preliminary demand analysis and design objectives as well as the corresponding functional requirements, five function modules are designed for the system, namely, map browsing module, data inquiry module, data management module, data statistics and analysis module, and comprehensive management module, etc.

\subsection{Map Browsing Function}

The map browsing module is the basic operation of WebGISbased map service. The base map of this system is called "Sky Map" as the background map, including the basic browsing functions such as zoom in, zoom out, roaming, hawk-eye map, full map, previous view, next view, etc. In addition, it also includes the functions of distance measurement, area measurement, projection transformation selection, map printing, etc.

\subsection{Data Management Functions}

The data management module is mainly for the comprehensive management of the database obtained from the preliminary benchmark land value work, and it is also an important core part of the system. The specific function is to obtain and display the basic geographic data, land value thematic data and other document image data stored in the database in the data management table in the front-end through the logical layer, and to realize the basic functions of data browsing, data addition, data editing, data deletion, data query and data export.

\subsection{Map Data Query Function}

The query of map data is a traditional business method of GIS system, specifically including spatial data query and attribute query, and based on the difference of methods can be divided into querying attributes through graphic location and querying spatial location through attributes. query. In addition to the query in the data management module, the attribute data can also be queried through the spatial graphic data or the corresponding single or multiple points of interest.

\subsection{Spatial Analysis and Statistical Functions}

The spatial analysis and statistics module is mainly for land value data, monitoring point data and sample point data to carry out numerical statistics, such as total, variance, mean, maximum and minimum values of land value, etc. In addition, according to some spatial analysis methods and models of GIS, the existing data can be analyzed and displayed in the form of some icons. Also, the comparison of land value data in different years forms a monitoring chart of the dynamic trend of the data, a comparison chart of land value data in different areas in the same year, etc. The functional module for analysis and statistics is the GP (Geographic Preprocessing and Modeling) service released by ArcGIS for Server, which operates by building geographic models. 


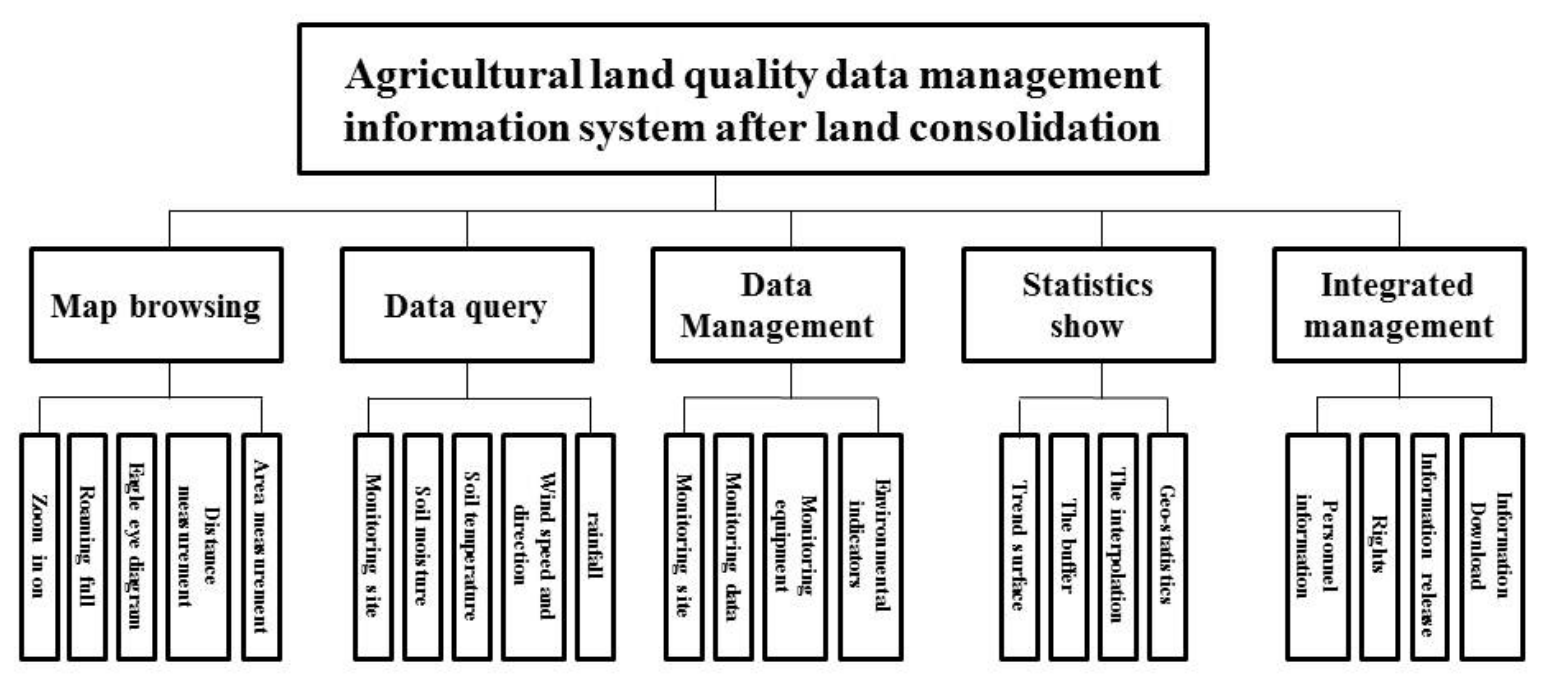

Figure 2. System function module chart

\section{System Demonstration and Conclusion}

This paper designs a GIS information system based on WebGIS principles for benchmark land value work, aiming to promote and help the development of benchmark land value work by combining cutting-edge GIS technology and new Web technology. The system is designed and developed by adopting JavaScript scripting technology as the core technology for the release, management and application of the benchmark land value data. The system designed in this paper is based on $\mathrm{B} / \mathrm{S}$ architecture and adopts the latest WebGIS technology and principles to realize a platform to share the data results obtained from the benchmark land value. Through relevant GIS analysis, users can clearly understand the dynamic changes of land value, and also provide more intuitive decision support for government departments.

\section{Acknowledgment}

The project was supported by a project grant from Shaanxi Land Construction - Xi'an Jiaotong University Land
Engineering and Human Settlement Technology Innovation Center Open Fund (2021WHZ0088) and Soil moisture inversion study of the Loess Plateau dry plateau based on SAR radar data (DJNY2022-23).

\section{References}

[1] Peng J. Research on geographic information publishing technology based on sliced map web service [D]. Zhejiang University, 2011.

[2] Connerly, Berger, Yu Jie. Database Design Tutorial [M]. Mechanical Industry Press, 2003.

[3] Fang Tiying. WebGIS design and implementation based on JavaScript technology [D]. Dalian: Dalian University of Technology, 2008.

[4] Li Gujun. Design and implementation of ArcGIS Server-based urban land value information dissemination system[D]. Jiangxi University of Technology, 2009.

[5] Gao, Haiming, Zhou, Wenqi. Design of a Web GIS-based land value information dissemination scheme for Ningbo. China Land Science[J], 2002, 16(2):20-25. 